\title{
Former co-chairs reminisce about their tenure
}

\section{What makes PAGES unique?}

\section{Bob Wasson (SSC, Vice-chair 1991-1996):}

My answer to this question lies in the history of attempts to get modernist scientists interested in the paleosciences. I have spent much of my career trying to get historical perspectives into natural resource management. I have had some success, but modernist scientists seem to think that all the history that is needed exists in instrumental records of a few decades in length. And now we have some saying that because of climate change, the past is no longer relevant to the future. This was recently claimed about the extreme bushfires in Australia in 2019/2020 because they are unprecedented. But without a long history how do we know they are unprecedented? And even if they are, histories provide the only means of assessing changes and their causes over sufficiently long periods to capture the full range of variability and which can be used to test forward-looking models.

I was drawn to PAGES because it was different. In traditional Quaternary research the international community was organized within INQUA (https://inqua.org), but to me that organization was valuable only for the paleoscientific community. It was not, as far as I could tell, well connected to modernist science or to decision making. This is where saw PAGES playing a role, and it has.

Tom Pedersen (SSC, Co-chair 1994-2002): From its outset, PAGES worked hard to embrace connectivity among scientists from all corners of the globe. It reached beyond the more typically dominant NorthernHemispheric pool of paleoscientists to tap talent in developing countries, particularly in the global south. Plus, it vigorously promoted and encouraged the participation of young developing-country scientists in PAGES-supported research and workshop activities. Such efforts were rooted in a firm two-pronged recognition that the phrase "Global Changes" in the PAGES acronym conveyed importance both geographic AND social. I think the PAGES community saw the need to bring all corners of the planet to the table to map not just paleoclimatic data but also the impacts of both short and long-term climate changes on the evolution of species (including $\mathrm{H}$. sapiens).

\section{Julie Brigham-Grette (SSC 2000-2008,} Chair 2004-2008): PAGES is unique in bringing together diverse minds, cultures, training, and expertise to the scientific issues, especially documenting how knowledge of past climate change informs the Earth systems' approach to understanding our future. PAGES has unified paleoclimate scientists into a global network, loaded with positive space for collaborations.

Heinz Wanner (SSC, Co-chair 2005-2010): Above all, it is the unique collaboration between enthusiastic scientists of many different disciplines with different interests and different careers: experimentalists and modelers, geoscientists, physicists, chemists, biologists, environmental historians, socio-anthropologists, etc. The format with focused workshops, the edition of white papers and joint publications as well as the organization of field experiments and modeling activities is a great success. An additional strength and success is the inclusion of young scientists from all around the globe. This also guarantees a longlasting and sustainable collaboration and network.

Without any doubt the high-standard Past Global Changes Magazine (earlier called PAGES news) brought people together in order to promote new ideas and new projects. The fact that this magazine is usually focused on a specific topic that is addressed by short, high-quality articles arouses the interest of a wide readership.

Hubertus Fischer (Co-chair 2011-2016): For me the uniqueness of PAGES comes from its interdisciplinary and bottom-up nature. It is thanks to the sense of responsibility of the PAGES researchers for safeguarding our planet, paired with their strong curiosity, that they again and again came up with and tackled frontier research questions that are located within the large range of the triangle of climate change, environmental response, and human action. Moreover, most of the working groups and their members have been open to other perspectives from outside their own area of expertise, which made truly new knowledge generation possible. This is reflected by the large range and interdisciplinary composition of the many working groups that PAGES supported over the last 30 years. The large number of new ideas made the life of the PAGES Scientific Steering Committee members easy, as the science plan developed naturally without losing its direction to contribute to the recent global change question. On the other hand, it made the life of the members difficult as they had to choose from a large number of excellent working group proposals to make best use of the limited financial means of PAGES. Looking back at the amount of top-notch science that emerged, its impact on global change knowledge using a rather small amount of money is huge. PAGES has definitely been one of the most successful enablers of science.

Sherilyn Fritz (SSC 2012-2017, Co-chair 2016-2017): PAGES' flexible structure for facilitating community-driven science makes it unique. This structure has allowed PAGES and the PAGES community to adapt grow, and evolve as the scientific questions and tools of paleoscience have evolved over time.

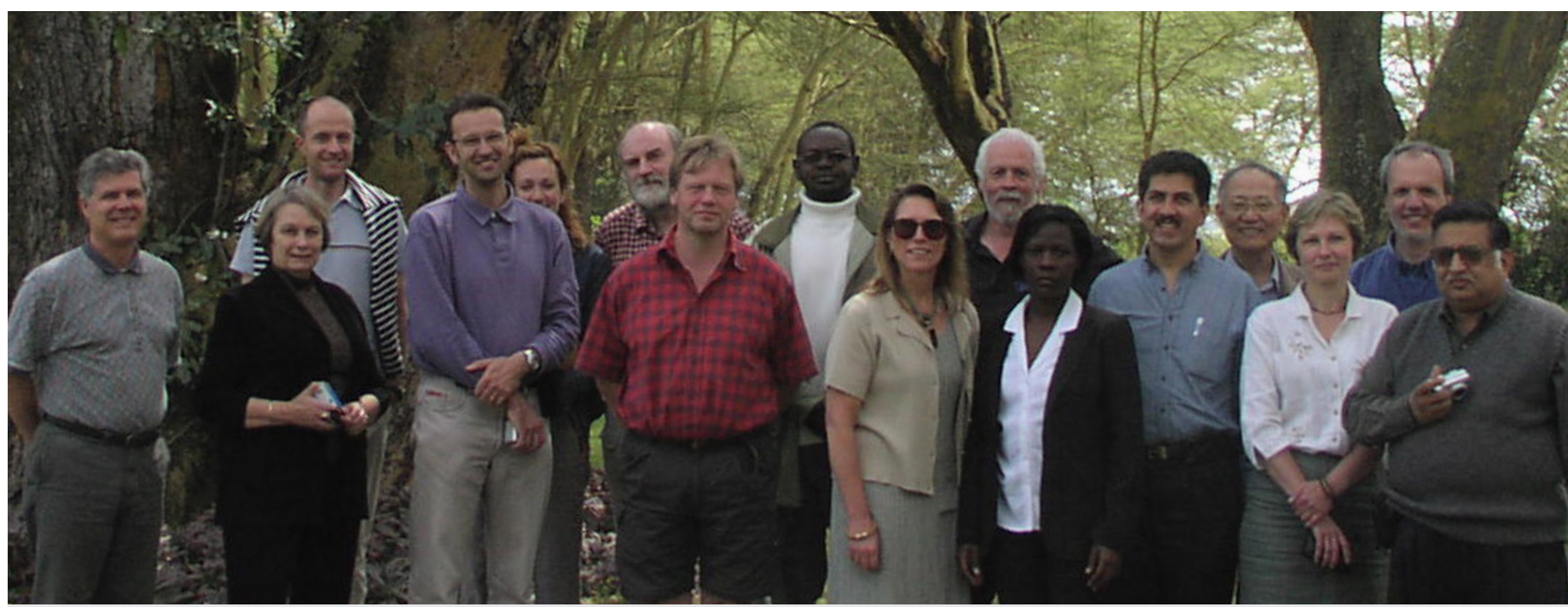

Figure 1: PAGES Scientific Steering Committee in Naivasha, Kenya, July 2004. L to R: João Morais (IGBP), Carole Crumley, Christoph Kull, Jérôme Chappellaz, Leah Witton, Rick Battarbee, Frank Sirocko, Dan Olago, Julie Brigham-Grette, Peter Kershaw, Rosemarie Otieno, José Martinez, Pinxian Wang, Olga Solomina, Ricardo Villalba, Ashok Singhvi. 


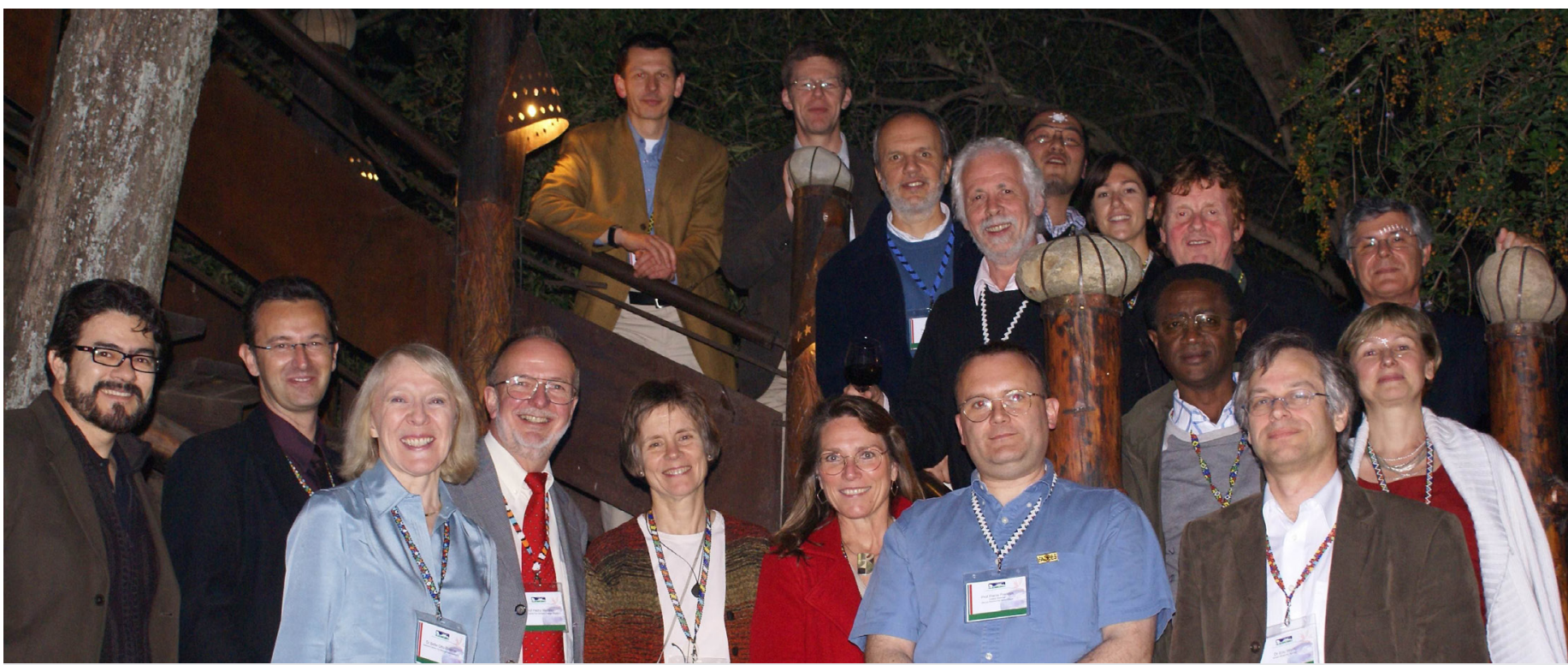

Figure 2: PAGES Scientific Steering Committee in Cape Town, South Africa, May 2008. Front (L to R): José Carriquiry, Jérôme Chappellaz, Bette Otto-Bliesner, Heinz Wanner, Cathy Whitlock, Julie Brigham-Grette, Pierre Francus, Eric Wolff; middle: Mohammed Umer, Olga Solomina (IGBP); back: Michael Schulz, Thorsten Kiefer, Ricardo Villalba, Peter Kershaw, Takeshi Nakatsuka, Louise Newman, John Dearing, João Morais (IGBP).

\section{What has been PAGES' most significant} accomplishment over the past 30 years?

Bob Wasson: The provision of high quality paleoclimatic records as test beds for global models is one accomplishment. The value of such research has recently been highlighted in Tierney et al. (2020). It is also noteworthy that within a global change program, PAGES has tried to put equal emphasis on climate change and land-use/land-cover change, but often the former won the lion's share of attention. However, I note that in the current science structure humans play an equal role with climate and environment, but I wonder if they really do receive equal attention.

Tom Pedersen: Back in the '90s and early 2000 s, I'd say that PAGES' most significant contributions in its first decade were at least threefold:

- PAGES quickly became a "go to" body for scientists from developing countries who sought to contribute to the international community but who had difficulty in finding a pathway in. PAGES helped to open that pathway and in doing so it elevated the importance of developing-country scientific efforts in helping us understand how the Earth has worked.

- In the mid-1990s PAGES set out to produce a high-quality science-focused newsletter which is much more than just a newsletter-it's a freely accessible publication of high quality that presents leading-edge science. While not carrying the heft of a peer reviewed journal, it does present a plethora of scientific insights to the global community and it does so at no cost to the community. Thus, it's a particularly valuable resource in developing countries. Moreover, it very often gives scientists in those countries a venue for publication that would otherwise be less open to them. There is great value in that value that continues to this day.

I'll add a wee anecdote here from the mid1990s. I remember that when we were discussing how best to strengthen what was the PAGES news (later renamed Past Global Changes Magazine), we agreed that we would never (make that NEVER!) include photographs of SSC members holding wine glasses at some sort of reception at a conference. Other international scientific and social-scientific bodies at that time also produced newsletters, but too often - at least in the view of those of us on the SSC at the time - their lead newsletter page featured a photo of some wine-glass-holding participants that looked like they were at a wellheeled soiree. We agreed that such photos send the wrong message, and we decided instead to put some insightful or thought-provoking scientific image on the front page. That approach was more in keeping with what we saw then as the PAGES philosophy. I think that perspective continues to prevail.

- A major contribution in the early days was the effort to support attendance of young scientists from developing countries at work shops, summer schools and conferences. We put significant resources into that effort and I'd like to think that it helped to launch the careers of young scholars by introducing them to international scientific networks and face-to-face dialog in their fields. I don't have hard evidence to support this contention but I hope it's a fair extrapolation.

Julie Brigham-Grette: PAGES has played a key role in driving shared scientific products that inform the IPCC process. It's important to remember that IPCC assessments did not always have a paleo-rich chapter, but the baseline perspective provided by paleodata spoke for itself. PAGES has fostered the development of syntheses across a variety of both spatial and temporal scales in paleoscience, driving model improvements and collaborative model development. It has also seeded international diplomacy, scientist to scientist, with capacity building and networking in countries where science is not well supported.

Heinz Wanner: Due to the aforementioned collaboration of a broad interdisciplinary community, PAGES was able to ask scientific questions of high significance and interest. With the slogan "exploring the past to understand the future" PAGES launched a number of very successful and projects with high impact. In the early years of PAGES, it was the Pole-EquatorPole (PEP) initiative. Several joint publications bear witness to the fundamental work within PEP. In recent years, several PAGES projects were very successful and have also had a large public impact, e.g. SynTRaCE-21, Past Interglacials (PIGS), and the PAGES 2k Network.

Hubertus Fischer: The overarching objective of PAGES was and is to shed light on the ongoing anthropogenic climate and environmental changes from a paleo perspective. This is based on the recognition of the early PAGES heroes (such as Hans Oeschger, John Eddy, Herman Zimmerman, and many others) and the PAGES science plans over the last 30 years that many of the Earth system processes act on timescales that are much longer than the direct instrumental record, in particular when it comes to the ocean, ice sheets, and global biogeochemical cycles. Thus, true sustainability research cannot be accomplished without the paleo perspective. Accordingly, I think the largest accomplishment of PAGES is that it was at least instrumental, if not essential for paleoscience to become a fully recognized and integrated part of climate change sciences over the last 30 years, which made tremendous contributions to our understanding of Earth system processes. Unfortunately, all of this paleo knowledge essentially implies that the Earth system cannot by itself provide sufficient negative feedbacks to the anthropogenic greenhouse gas effect to guarantee a safe operating space for sustainable human action without strong mitigation as well as adaptation measures.

\section{Sherilyn Fritz: PAGES' accomplishments} include

- multiple high-impact synthesis products that address broad-scale and important science questions; and

- an increasingly interconnected, diverse, inter national paleoscience community. 


\section{What should PAGES do in its 4th decade?}

\section{Bob Wasson:}

- Many of the questions PAGES set out to answer will engage international science for years to come, especially in the development of better paleoclimatic records and explanations of their variability. Much progress has been made in producing high-resolution records and this needs to continue, particu larly focused on rapid change and extreme events. The latter has direct societal relevance as environmental disasters continue to increase worldwide. But disasters only occur when hazards such as floods and cyclones affect people. This means that social science and human history need to be involved in any work on long records of hazards and the disasters that result when people are vulnerable and exposed.

- The current science structure gives some attention to the links and feedbacks between components of the Earth system. From my experience such an approach requires an analytical framework that obliges individual researchers to commit to a cohesive analysis. If such a framework is not available, all you end up with is juxtaposition of skills with little dynamic interaction. For me system dynamics is the ideal framework.

- It is my view that many in the Quaternary community apply a naïve determinism when correlating societal change with paleoclimatic or, more generally, paleoenvironmental change. The criticism of the idea of societal "collapse" underscores this point, suggesting that transformation occurs when climate change or resource depletion force societal change. For scientists with no training in the social sciences or history, to declare that correlation is causal without serious analysis does our field no favors. Recent ideas about how to analyze relationships between environmental and societal change can be found in an article by White and Pei (2020). PAGES needs to find ways to make this field of research more sophisticated, in the first instance by including social scientists and historians in the SSC.

- While I was associated with PAGES, we tried very hard to fill some of the spatial data gaps, particularly in Africa and Asia, but with limited success. This effort needs to continue.

- If PAGES is to meet its full potential it must be welcoming to social scientists and historians, including, particularly, environmental historians. The current SSC has no social scientists or historians, but I acknowledge that such disciplines have been involved in PAGES activities in the past. But without such voices in the SSC, I suggest that PAGES cannot expect to fully cover its scientific program and therefore realize its full potential.

Tom Pedersen: It might be facile, but I'd have to say, "Stay the course." PAGES has much of which it can be proud. It is justifiably highly regarded in developing countries and it has filled a need that otherwise might not have been filled. There is one other point l'd like to make. PAGES has been continually supported by Switzerland (which I salute). But where is support from other developed countries? Back in the '90s we had a strong ally in the US NSF (Herman Zimmerman) who as program director recognized the value of international networks in science. When he stepped down in 1996, PAGES lost a key ally, and I remember having to deal with NSF program directors after him who, frankly, held provincial views that constrained their willingness to recognize that globalchange science was actually, well, global, and not just American. The Americans weren't alone - I had trouble in Canada as well in those days in trying to convince our government to meet the challenge. I'm still embarrassed by that; worse, it hasn't changed.

So, I think a big challenge for PAGES in its fourth decade is to broaden its support base. That will be even more difficult in the postcoronavirus-recovery era, but being difficult doesn't mean progress can't be made. It will require sustained high-level diplomatic effort. That's a big challenge for any SSC but it's one worth pursuing.

Julie Brigham-Grette: Continue with outstanding working groups and focused projects (discovery science) but also don't be afraid to develop a framework for actionable science that others can use for policies. We must also be an international community for change, adapting JEDI principles of justice, equity diversity, and inclusion.

Heinz Wanner: Let us again focus on exciting (and also longer-term) projects involving proxy people and modelers. The collaboration with the PMIP-CMIP community is important. It makes sense to concentrate on important past time periods that offer insights into key processes of the climate system. We should not be too modest and also launch large projects and programs. Beyond EPICA Oldest Ice (beyondepica.eu) is such a lighthouse project.

Hubertus Fischer: This is probably the most difficult question. Of course PAGES could and will continue to produce frontier paleoscience results in the field of climate change research. However, while the ever-increasing need for immediate action to mitigate climate change requires knowledge transfer to practitioners and policy makers, many of the PAGES working groups and experts are strongly rooted in academia and less so in applied science. The challenge for PAGES will therefore be to bridge from its strong roots in natural sciences to its application without losing its scientific credibility. As an example, I point here to climaterelated ecosystem changes that are required in forestry and agriculture to warrant a sustainable use of natural resources and ecosystem services. Unfortunately, the paleo knowledge of sustainable ecosystem use is not (always) in line with current practice or apparent economic needs, as long as such ecosystem services and the costs for sustainable use are not included and remunerated. In essence, the challenge for PAGES will be to not lose its scientific strength while at the same time not retreating into the academic ivory tower - a task that is especially challenging for early-career scientists who still have to establish themselves on the science stage. I wonder what instruments PAGES as an organization can offer to build this bridge.

Sherilyn Fritz: PAGES should continue to foster innovative interdisciplinary communitydriven science syntheses.

\section{REFERENCES}

Tierney JE et al. (2020) Science 370: eaay3701

White S, Pei Q (2020) PAGES Mag 28: 44-45

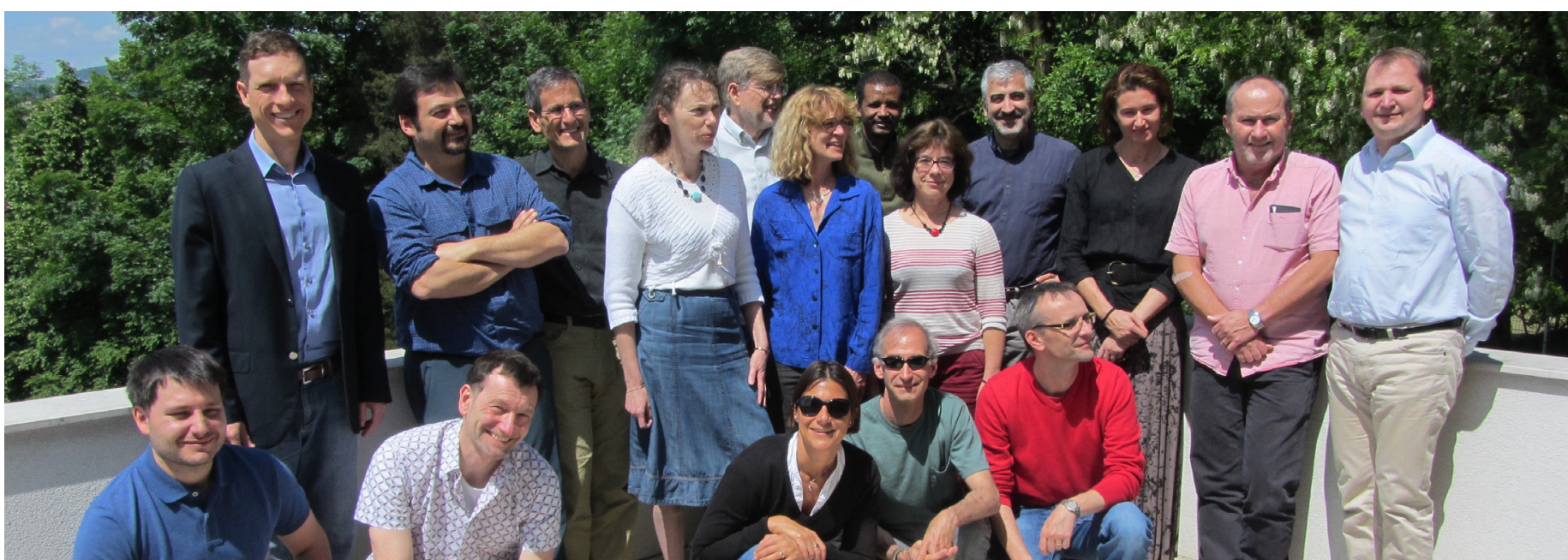

Figure 3: PAGES Scientific Steering Committee in Cluj-Napoca, Romania, May 2016. Front (L to R): Lucien von Gunten, Hubertus Fischer, Katrin Meissner, Mike Evans, Hugues Goosse. Back: Cristiano Chiessi, Claudio Latorre, Darrell Kaufman, Marie-France Loutre, Dave Carlson (WCRP), Sherilyn Fritz, Asfawossen Asrat, Pascale Braconnot, Blas ValeroGarcés, Lindsey Gillson, Peter Gell, Michal Kucera. 